\title{
A Simple and Efficient Molecularly Imprinted Electrochemical Sensor for the Selective Determination of Tryptophan
}

\author{
Yaling Tian ${ }^{1,2,+}$, Peihong Deng ${ }^{2, *}$, Yiyong $W u^{1,2,+}$, Ziyu Ding ${ }^{1,2,+}$, Guangli Li ${ }^{1} \mathbb{D}$, Jun Liu ${ }^{1,2}$ \\ and Quanguo $\mathrm{He}^{1, *}$ \\ 1 School of Life Sciences and Chemistry, Hunan University of Technology, Zhuzhou 412007, China \\ 2 Hunan Provincial Key Laboratory of Functional Metal-Organic Compounds; Key Laboratory of Functional \\ Organometallic Materials of Hunan Provincial Universities; Department of Chemistry and Material Science, \\ Hengyang Normal University, Hengyang, Hunan 421008, China \\ * Correspondence: dph1975@163.com (P.D.); hequanguo@126.com (Q.H.) \\ $\dagger$ These authors contributed equally to this work.
}

Received: 22 June 2019; Accepted: 17 July 2019; Published: 22 July 2019

check for updates

\begin{abstract}
In this paper, a tryptophan (Trp) molecularly imprinted chitosan film was prepared on the surface of an acetylene black paste electrode using chitosan as the functional polymer, Trp as the template molecule and sulfuric acid as the crosslinking agent. The surface morphologies of non-imprinted and imprinted electrodes were characterized by scanning electron microscopy (SEM). The formation of hydrogen bonds between the functional polymer and the template molecule was confirmed by infrared spectroscopy. Some factors affecting the performance of the imprinted electrode such as the concentration of chitosan, the mass ratio of chitosan to Trp, the dropping amount of the chitosan-Trp mixture, the solution $\mathrm{pH}$, and the accumulation potential and time were discussed. The experimental results show that the imprinted electrode exhibit good affinity and selectivity for Trp. The dynamic linear ranges of $0.01-4 \mu \mathrm{M}, 4-20 \mu \mathrm{M}$ and $20-100 \mu \mathrm{M}$ were obtained by second derivative linear sweep voltammetry, and the detection limit was calculated to be $8.0 \mathrm{nM}$. The use of the imprinted electrode provides an effective method for eliminating the interference of potentially interfering substances. In addition, the sensor has high sensitivity, reproducibility and stability, and can be used for the determination of Trp in pharmaceutical preparations and human serum samples.
\end{abstract}

Keywords: molecularly imprinted chitosan film; electrochemical sensor; tryptophan; selective determination

\section{Introduction}

Tryptophan (Trp) is an important amino acid for the human body. Low concentrations of Trp are essential for many physiological functions. It is a precursor of serotonin and melatonin that significantly improves the mood, sleep and mental health. It is also an important component of protein, capable of establishing and maintaining a positive nitrogen balance [1]. Because Trp is seldom found in vegetable products, this compound is sometimes added to diets, food, and pharmaceutical formulations. However, if Trp is excessively consumed or cannot be properly metabolized, high concentrations of Trp would have some harmful effects on the human body, such as producing a toxic waste in the brain, leading to hallucinations and delusions [2]. In addition, it may be a cause of schizophrenia for people. Because of its small thresholds between essential and toxic levels in living organisms, it is of great clinical significance to determine Trp simply, accurately and quickly. Besides, Trp often coexists with ascorbic acid (AA), dopamine (DA), uric acid (UA), nitrite $\left(\mathrm{NO}_{2}^{-}\right)$and other amino acids in biological matrixes. Therefore, the selective determination of Trp is also very important. 
At present, there are many analytical methods for Trp determination, such as liquid chromatography [3], gas chromatography [4] and thin layer chromatography [5]. Chromatographic techniques are highly selective and accurate, however, they often require pretreatment steps, expensive and complicated instruments, skilled operators as well as consume more time. Some non-chromatographic methods such as spectrophotometry [6], fluorescence [7] and chemiluminescence [8] are also used to determine Trp. However, they suffer from low selectivity. Derivative spectroscopy [9] and multivariate calibration techniques [10] are sometimes used to solve the problem of poor selectivity. Electroanalytical techniques have great appeal in monitoring biologically important molecules due to their simplicity, low cost, portability and sensitivity [11-15]. Because Trp can be oxidized on the electrode, recent studies have focused on the determination of Trp by electrochemical methods. However, the direct oxidation of Trp on bare electrodes results in slow electron transfer and high overpotentials [16]. Some chemically modified electrodes have been reported for the determination of Trp [16-27], and comparative analytical figures of merit for different electrodes are summarized in Table 1. Although these sensors can offer high sensitivity and a low detection limit, they suffer from the main drawback, which is the moderate selectivity. According to these studies, the oxidation peak potentials for some electroactive biomolecules, such as ascorbic acid (AA), uric acid (UA), dopamine (DA) and tyrosine (Tyr), are very close to that of Trp, and the voltammetric responses of Trp and these substances exhibit severe overlapping, which makes their practical applications limited. Since Trp often coexists with these biomolecules in food processing, pharmaceutical formulations and biological fluids, to determine Trp selectively based on its electroactivity is of great challenge.

In recent years, molecularly imprinted polymers (MIPs) have been widely used in various fields such as artificial antibodies, chemical sensors and solid phase extraction, due to their excellent selectivity, good chemical and physical stability, as well as low cost [28-30]. There are also increasing reports of using MIPs to modify the electrode surface to enhance selectivity [31-34]. In general, molecular imprinting is the process of polymerizing selected functional monomers around the template molecules in the presence of a cross-linking agent. After polymerization, the template molecules are extracted to obtain a polymer matrix that is complementary in shape and functionality to the template. Thus, the polymer has the ability to selectively attach to the analyte. Chitosan is a natural polymer (a polysaccharide) obtained by the partial deacetylation of chitin. Because of its excellent film forming ability, biocompatibility, biodegradability, lack of toxicity and low cost, chitosan has been widely used in membrane separation, drug delivery and environmental protection [35-37]. In addition, chitosan can chelate and adsorb with many substances based on a large number of hydroxyl groups and amino groups. In recent years, chitosan has also been reported for the construction of imprinted electrochemical sensors and shows good selectivity [38-41]. For example, Guo and his colleagues fabricated a novel molecularly imprinted electrochemical sensor modified with carbon dots, chitosan, and gold nanoparticles for the detection of patulin. The linear response range of the MIP sensor was from $1.0 \mathrm{pM}$ to $1.0 \mathrm{nM}$ and the limit of detection (LOD) was $0.757 \mathrm{pM}$ [38]. Wu et al. developed an electrochemical sensor based on ion-imprinted chitosan-graphene nanocomposites for the sensitive and selective determination of $\mathrm{Cr}(\mathrm{VI})$. The linear range of the MIP sensor was from $1.0 \mathrm{nM}$ to $10 \mu \mathrm{M}$, with a low detection limit of $0.64 \mathrm{nM}$ [39]. Liu et al. constructed a MIPs electrochemical sensor based on graphene-chitosan composite and used in dopamine measurements. The linear range was from $1.0 \mathrm{nM}$ to $80 \mathrm{nM}$ and $0.1 \mu \mathrm{M}$ to $100 \mu \mathrm{M}$. The sensor exhibited high selectivity for the determination of dopamine in the presence of some structural analogues and coexisting interferences [40]. Xia and his colleagues prepared a novel protein molecularly imprinted electrochemical sensor based on a chitosan/ionic liquid-graphene modified glassy carbon electrode via electrochemical polymerization, which could be used for the sensitive and selective detection of bovine serum albumin [41]. However, as far as we know, the design and fabrication of imprinted electrochemical sensors for Trp detection using chitosan have not been reported in any literature.

Many applications require not only better selectivity, but also higher sensitivity. Acetylene black (AB) has become an effective sensing platform for the development of electrochemical sensors and 
biosensors in recent years because of its unique advantages such as large specific surface area, good chemical stability, high mechanical strength and excellent conductivity [42,43]. In this paper, an electrochemical sensor with high sensitivity and selectivity for the voltammetric determination of Trp was developed by combining acetylene black with the molecular imprinting technique. Using natural chitosan as functional polymer and Trp as template molecule, Trp molecularly imprinted chitosan film was prepared on the surface of an acetylene black paste electrode (ABPE). Various factors affecting the electrochemical performance of the imprinted electrode were investigated in detail. The new sensor has the characteristics of good selectivity, simple preparation and easy operation. Finally, this MIP/ABPE was successfully applied to the quantitative analysis of Trp in pharmaceutical preparations and human serum samples.

\section{Experimental}

\subsection{Chemicals and Solutions}

Trp and other amino acids, uric acid, ascorbic acid, dopamine, sodium nitrite, oxalic acid, glucose, lactic acid, and tartaric acid were purchased from Aladdin Chemical Reagent Co., Ltd., Shanghai, China. Acetylene black (AB, purity $>99.99 \%$ ) was purchased from STREM Chemicals, USA. Chitosan (95\% deacetylation) was purchased from Shanghai Biochemical Co. Ltd., China. The human blood serum samples were obtained from a local hospital. The standard stock solution $\left(1.0 \times 10^{-3} \mathrm{M}\right)$ of $\operatorname{Trp}$ was prepared by dissolving Trp into $0.1 \mathrm{M} \mathrm{HCl}$ and diluting to $100 \mathrm{~mL}$ with water, which was stored at $4{ }^{\circ} \mathrm{C}$ and was stable for two weeks. The working solution was freshly prepared before use by diluting the stock solution. All other reagents were of analytical grade and used directly. The water used was doubly distilled.

\subsection{Apparatus}

The morphologies of the non-imprinted and imprinted films were observed by a scanning electron microscope (EVO10, ZEISS, Jena, Germany). Fourier transform infrared spectroscopic measurements were performed on an IRPrestige-21 Fourier transform infrared spectrometer (Shimadzu Corp., Tokyo, Japan). Cyclic voltammetry (CV) was carried out on a CHI 660D electrochemical workstation (Chenhua Instrument Co. Ltd., Shanghai, China) controlled by a microcomputer with CHI660 software. A model JP-303E polarographic analyzer (Chengdu Instrument Factory, Chengdu, China) was used to give the second-order derivative linear sweep voltammograms for electroanalytical measurements. A three-electrode system was used thoughout the electrochemical measurements, where the MIP/ABPE was used as the working electrode, a platinum wire as the counter electrode and a saturated calomel electrode (SCE) as the reference electrode. All potentials reported were versus the SCE. pH measurements were performed with a pH-3c Model pH meter (Shanghai Leichi Instrument Factory, Shanghai, China) using a combined glass electrode.

\subsection{Preparation of $M I P / A B P E$}

A total of $1.20 \mathrm{~g}$ of acetylene black powder and $0.30 \mathrm{~g}$ of solid paraffin were ground uniformly in a mortar. Subsequently, the mixture was heated to $75-80^{\circ} \mathrm{C}$ to melt the solid paraffin. The homogenous paste was tightly pressed into an electrode tube $(1.0 \mathrm{~mm}$ in diameter and $3.0 \mathrm{~mm}$ in depth) while it was hot. The surface of the electrode was polished on a weighing paper to remove the excess of solidified material. For the preparation of the MIP/ABPE, $50.0 \mathrm{mg}$ of chitosan was dissolved in $10.0 \mathrm{~mL}$ $1.0 \%(v / v)$ acetic acid aqueous solution. At the same time, a certain amount of template molecule Trp was added. The mixed solution was stirred at room temperature for $4 \mathrm{~h}$. Subsequently, $5 \mu \mathrm{L}$ of the obtained solution was drop-coated onto the ABPE surface and the solvent was left to evaporate under ambient conditions. Then the chitosan film was cross-linked by immersing the modified electrode into a $0.5 \mathrm{M}$ sulfuric acid solution at room temperature for $24 \mathrm{~h}$ [44]. After that, the modified electrode was subjected to a washing procedure by repetitive immersion in ethanol to remove the Trp template 
entrapped in the polymeric matrix, and then air-dried for $24 \mathrm{~h}$. The obtained imprinted electrode was tagged as MIP/ABPE. The entire process of electrode preparation was shown in Scheme 1. As a control, the non-imprinted electrode (NIP/ABPE) was prepared with the same procedure just without adding the template molecules. In order to show their unique properties, $\mathrm{AB}, \mathrm{MIP} / \mathrm{CPE}$ (CPE refers to carbon paste electrode throughout the following text) and NIP/CPE, were also prepared in a similar manner, only graphite powder was needed to replace acetylene black powder.

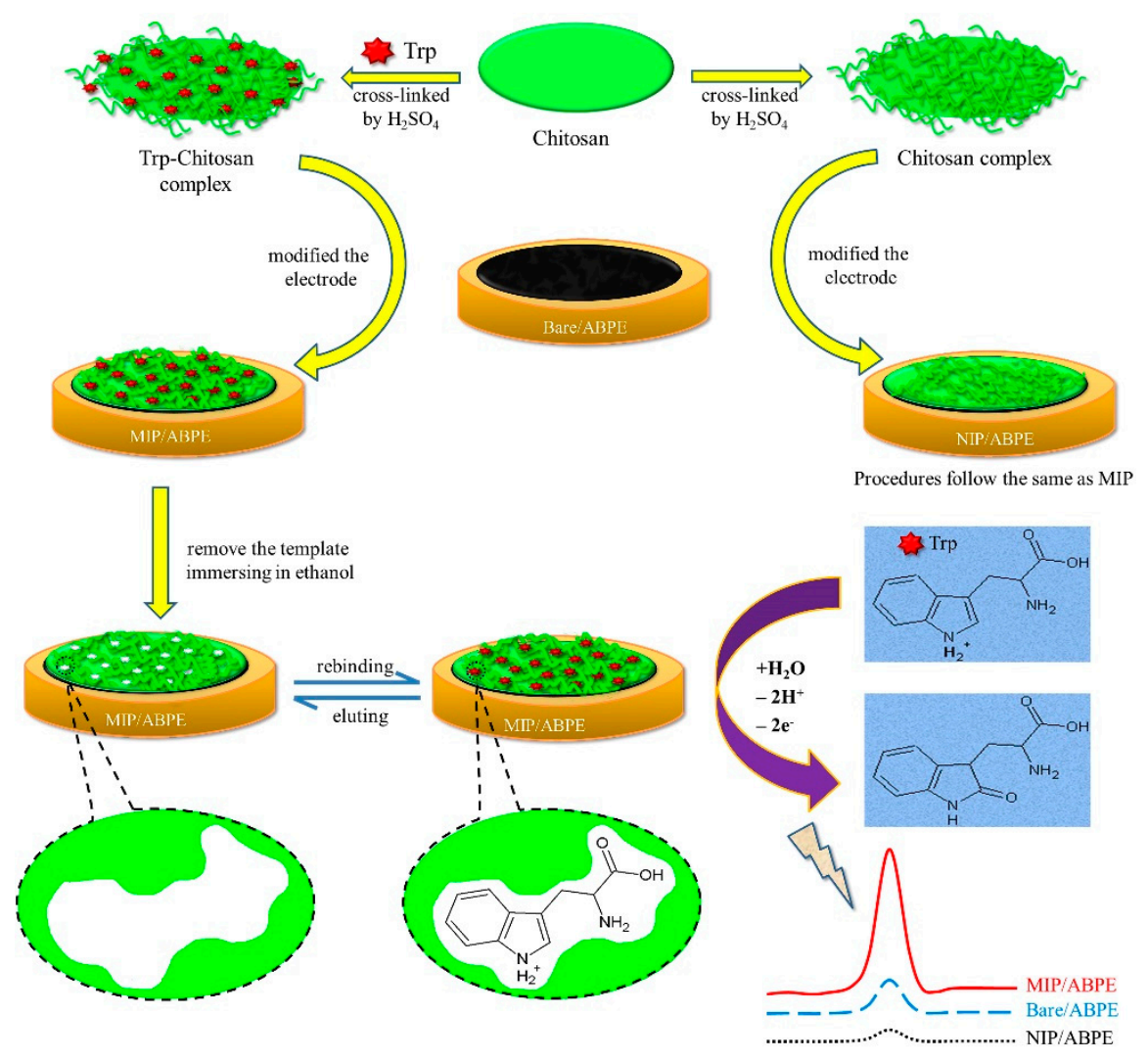

Scheme 1. The procedure for fabrication of the molecularly imprinted polymers (MIP)/acetylene black paste electrode (ABPE).

\subsection{Electrochemical Measurements}

All electrochemical experiments including cyclic voltammetry (CV) and second-order derivative linear sweep voltammetry were carried out with a standard three-electrode system, using bare or modified electrodes, a platinum wire electrode, and a saturated calomel electrode (SCE) as the working electrode, counter electrode and reference electrode, respectively. The CV was used for the electrode characterization in a solution consisting of $1.0 \mathrm{mM} \mathrm{K}_{3}\left[\mathrm{Fe}(\mathrm{CN})_{6}\right]$ and $0.5 \mathrm{M} \mathrm{KCl}$. The sensing performance of Trp on MIP/ABPE and the optimization of measuring conditions, as well as the selectivity, reproducibility and stability experiments, were carried out by second-order derivative linear sweep voltammetry. A $10.0 \mathrm{~mL}$ volume of the solution, containing an appropriate concentration of Trp and $0.1 \mathrm{M}$ phosphate buffer ( $\mathrm{pH}$ 7.0) was transferred into a voltammetric cell. The stirrer was switched on. The accumulation potential of $-0.1 \mathrm{~V}$ was applied to the MIP/ABPE for $180 \mathrm{~s}$. Following the accumulation period, the stirrer was stopped, and after a rest period of $5 \mathrm{~s}$, the second-order derivative voltammogram was recorded by applying a positive-going potential scan from 0.2 to $1.2 \mathrm{~V}$ at $0.1 \mathrm{~V} \mathrm{~s}^{-1}$, and the second derivative peak of Trp was obtained at about $0.756 \mathrm{~V}$. After each measurement, the imprinted electrode was immersed in a $0.1 \mathrm{M}$ phosphate buffer ( $\mathrm{pH} 7.0)$ and treated with repetitive potential scanning from 0.2 to $1.2 \mathrm{~V}$ at a scan rate of $0.1 \mathrm{~V} \mathrm{~s}^{-1}$ to remove the template molecules until the baseline became stable. To demonstrate the MIP/ABPE repeatability, the results were averaged for three measurements at the same electrode. All the measurements were performed at room temperature. 


\section{Results and Discussion}

\subsection{Template Removal}

Figure 1 shows the CVs of the MIP/ABPE and NIP/ABPE in a $0.1 \mathrm{M}$ phosphate buffer (pH 7.0) with the potential ranging from 0.2 to $1.2 \mathrm{~V}$. Before extracting the template molecules, a broad oxidation peak at about $0.80 \mathrm{~V}$ could be seen (curve a). Because the electrochemical measurement was carried out in a Trp-free solution, this means that the oxidation peak was caused entirely by Trp embedded in the chitosan film. When MIP/ABPE was immersed in ethanol and the Trp template molecules were removed from the chitosan matrix, almost no electrochemical response is observed, as shown in curve b. The disappearance of the CV signal indicates that Trp is effectively removed. No peaks are observed at the NIP/ABPE (curve c).

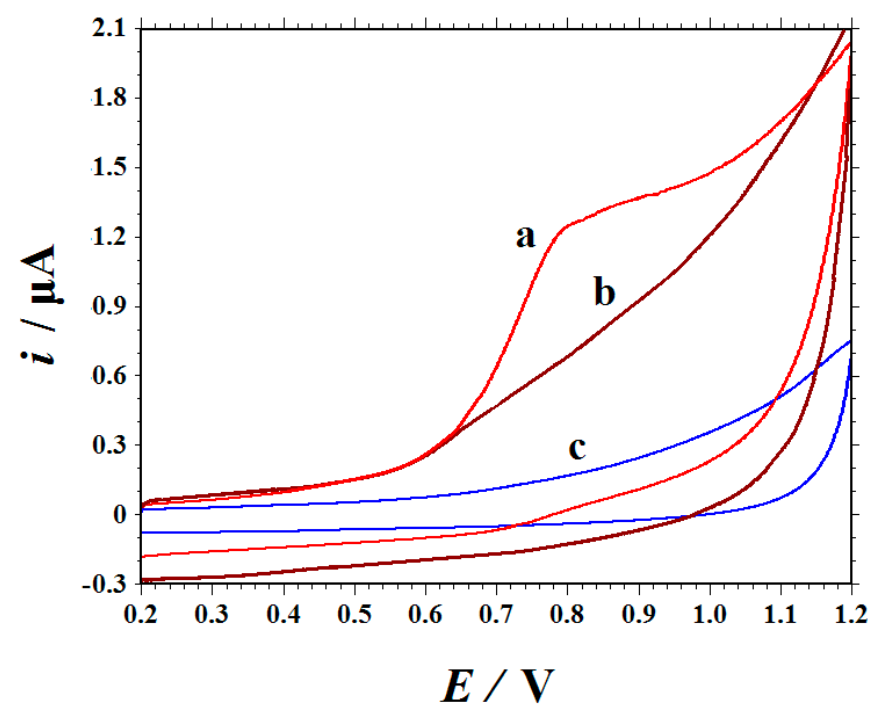

Figure 1. The cyclic voltammograms in the $0.1 \mathrm{M}$ phosphate buffer ( $\mathrm{pH} 7.0$ ) recorded on the molecularly imprinted polymers (MIP)/acetylene black paste electrode (ABPE) before extraction (curve a) and after extraction (curve b), non-imprinted electrode (NIP)/ABPE (curve c). Scan rate: $0.1 \mathrm{~V} \mathrm{~s}^{-1}$.

\subsection{FT-IR Spectra}

Figure 2 displays the Fourier Transform Infrared FT-IR spectra of chitosan, Trp and the chitosan-Trp composite. The spectrum of chitosan (Figure 2a) showthe absorption peaks at about $3350 \mathrm{~cm}^{-1}$ for the $-\mathrm{NH}_{2}$ and $-\mathrm{OH}$ groups, at about 2920 and $2879 \mathrm{~cm}^{-1}$ for the aliphatic $\mathrm{C}-\mathrm{H}$ stretching vibration, $1647 \mathrm{~cm}^{-1}$ for the absorption peak of the rest $\mathrm{NH}_{2} \mathrm{CO}$ group, and $1077 \mathrm{~cm}^{-1}$ for the $\mathrm{C}-\mathrm{O}$ group. Figure $2 \mathrm{~b}$ demonstrates the FT-IR of Trp. A strong and sharp peak is observed at $3404 \mathrm{~cm}^{-1}$, which corresponds to the N-H stretching in the indole group of Trp, and two poor resolved bands between 3078-3038 $\mathrm{cm}^{-1}$ correspond to the asymmetric and symmetric stretching modes of the amino group. IR bands observed at 1667 and $1589 \mathrm{~cm}^{-1}$ correspond to the $\mathrm{COO}^{-}$and $\mathrm{NH}_{3}{ }^{+}$asymmetric stretching vibrations, respectively. The peaks at 1456, 1414 and $1356 \mathrm{~cm}^{-1}$ are assigned to the $\mathrm{NH}_{3}{ }^{+}$symmetric stretching vibration, the $\mathrm{COO}^{-}$symmetric stretching mode and the $\mathrm{C}-\mathrm{H}$ deformation mode, respectively [45]. In Figure 2c, the broaden absorption peak at about $3500-3000 \mathrm{~cm}^{-1}$ corresponds to the hydrogen bond strength. In comparison with that of Figure 2a, the $\mathrm{C}=\mathrm{O}$ absorption peaks moved from 1647 to $1633 \mathrm{~cm}^{-1}$. These changes are due to the formation of hydrogen bonds between the functional polymer and the template molecule. 


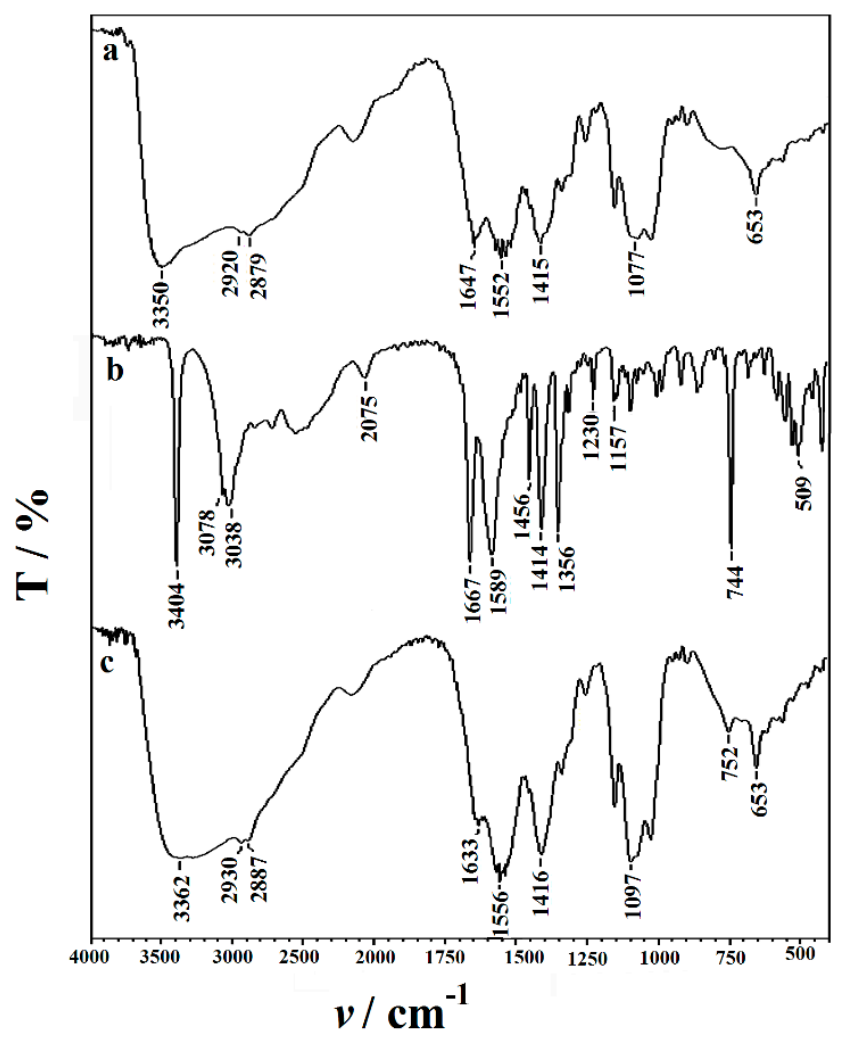

Figure 2. The Fourier Transform Infrared (FT-IR) spectra of (a) chitosan, (b) Trp and (c) the Trp-chitosan composite.

\subsection{Electrode Characterizations by SEM and CV}

The surface morphologies of ABPE, NIP/ABPE and MIP/ABPE were studied by scanning electron microscopy (SEM). As shown in Figure 3A, the surface of ABPE is rough and uneven, and AB particles show an irregular and large flake structure. The surface of NIP/ABPE is smooth and flat (Figure 3B), which is attributed to the formation of a compact chitosan film on the electrode surface. As illustrated in Figure 3C, the top view of MIP/ABPE changes significantly compared to NIP/ABPE. After removing the template molecules, a three-dimensional network porous structure is observed on the MIP/ABPE, indicating that the specific cavities are formed in the chitosan matrix.
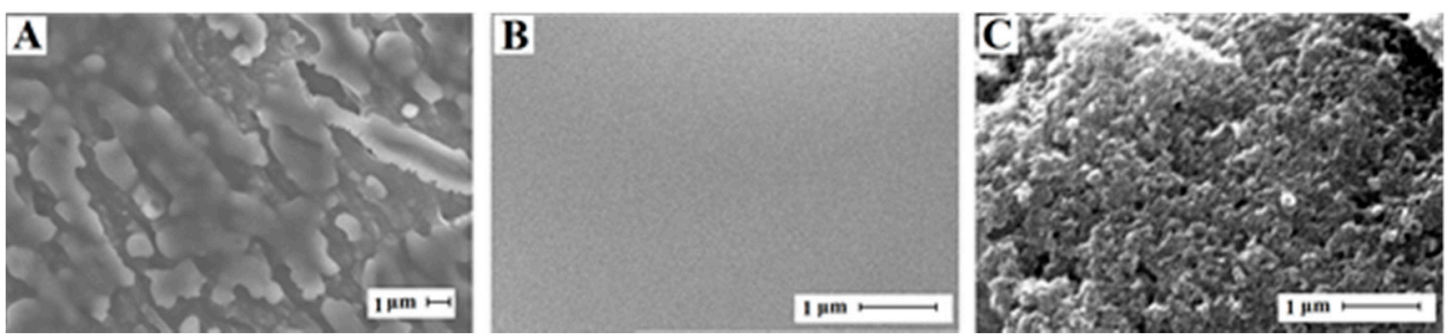

Figure 3. The scanning electron microscopy (SEM_ images of (A) ABPE, (B) NIP/ABPE and (C) MIP/ABPE.

The cyclic voltammetric behaviours of $1.0 \mathrm{mM} \mathrm{K}_{3}\left[\mathrm{Fe}(\mathrm{CN})_{6}\right]$ containing $0.5 \mathrm{M} \mathrm{KCl}$ at different electrodes were studied at a scan rate of $0.1 \mathrm{~V} \mathrm{~s}^{-1}$. Figure 4 shows the corresponding cyclic voltammograms obtained at CPE (curve a), ABPE (curve b), MIP/ABPE before and after extraction of the template molecules (curve $c$ and cruve d), respectively. $\mathrm{K}_{3}\left[\mathrm{Fe}(\mathrm{CN})_{6}\right]$ shows a pair of quasi-reversible $\mathrm{CV}$ peaks on bare CPE. The cathodic peak potential $\left(E_{\mathrm{pc}}\right)$ is $111 \mathrm{mV}$, the anodic peak potential $\left(E_{\mathrm{pa}}\right)$ is $302 \mathrm{mV}$, and the peak separation $\left(\Delta E_{\mathrm{p}}\right)$ is $191 \mathrm{mV}$. Compared with bare CPE, the peak current of 
$\mathrm{K}_{3}\left[\mathrm{Fe}(\mathrm{CN})_{6}\right]$ on ABPE increases significantly and the peak separation decreases to $75 \mathrm{mV}$, indicating that $\mathrm{AB}$ can improve the electron transfer rate in the redox process of $\left[\mathrm{Fe}(\mathrm{CN})_{6}\right]^{3-/ 4-}$. This is because $\mathrm{AB}$ has good conductivity and a large specific surface area, which provides a suitable bed for MIP immobilization. Before Trp extraction, the CVs of MIP/ABPE show two distinct redox peaks, the current is higher than that of ABPE, and the peak separation is $99 \mathrm{mV}$. This may be due to the affinity of positively charged chitosan to negative charge $\left[\mathrm{Fe}(\mathrm{CN})_{6}\right]^{3-/ 4-}[46]$. As compared with MIP/ABPE before Trp extraction, the current of MIP/ABPE after Trp extraction increases further. This can be explained because when Trp is extracted from the chitosan film, the three-dimensional imprinted cavities matching with Trp is formed not only in the spatial structure, but also in the functional groups. With these cavities, $\left[\mathrm{Fe}(\mathrm{CN})_{6}\right]^{3-/ 4-}$ can easily reach the surface of ABPE through the chitosan film due to its small size. Therefore, the increase in current observed at MIP/ABPE is attributed to the imprinting characteristics.

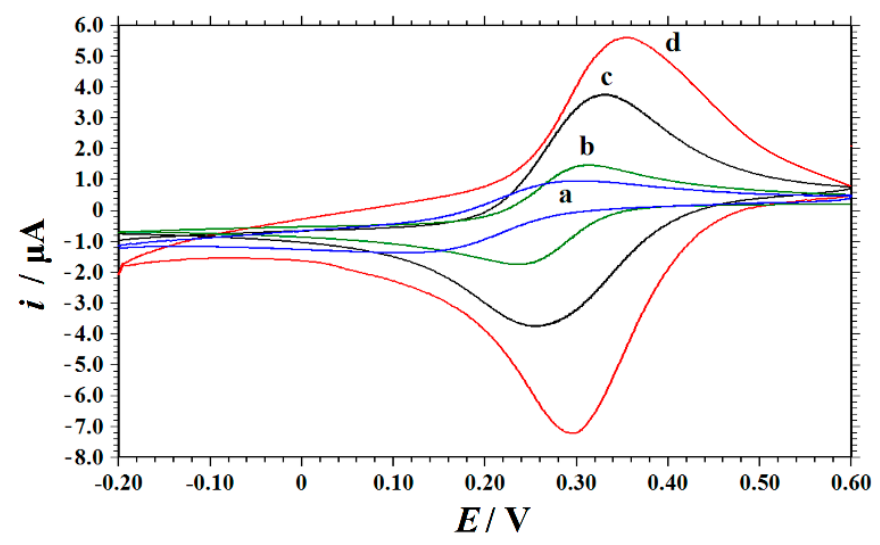

Figure 4. The cyclic voltammograms obtained at different electrodes in the $1.0 \mathrm{mM} \mathrm{K}_{3}\left[\mathrm{Fe}(\mathrm{CN})_{6}\right]$ solution containing $0.5 \mathrm{M} \mathrm{KCl}$. (a) CPE, (b) ABPE, (c) MIP/ABPE before extraction, (d) MIP/ABPE after extraction. Scan rate: $0.1 \mathrm{~V} \mathrm{~s}^{-1}$.

\subsection{The Imprinting Effect and the Electrode Process Mechanism}

The extraction of Trp results in the formation of sites in the chitosan matrix that can selectively recombine the template molecules. The affinity and selectivity of the imprinted electrode were evaluated by second derivative linear sweep voltammetry. In comparison with differential pulse voltammetry (DPV) and square wave voltammetry (SWV), the second derivative linear sweep voltammetry has a higher current, better signal to background characteristics and better resolution of overlapping [42,43]. Figure 5 shows the second derivative linear sweep voltammetry of Trp oxidation at CPE (curve a), ABPE (curve b), MIP/CPE (curve c), MIP/ABPE (curve d) and NIP/ABPE (curve e) after accumulation at $-0.1 \mathrm{~V}$ for $60 \mathrm{~s}$ in a $0.1 \mathrm{M}$ phosphate buffer ( $\mathrm{pH}$ 7.0) containing $0.1 \mathrm{mM}$ Trp. Obviously, CPE has the lowest peak current $(914 \mathrm{mV}, 0.02781 \mu \mathrm{A})$. When ABPE is used, the peak current of Trp increases $(796 \mathrm{mV}, 0.1953 \mu \mathrm{A})$ due to the specific surface area and special electrical performance of $\mathrm{AB}$. The current responses of MIP/CPE $(804 \mathrm{mV}, 0.1256 \mu \mathrm{A})$ and MIP/ABPE $(756 \mathrm{mV}, 0.8226 \mu \mathrm{A})$ are significantly higher than those of CPE and ABPE, which could be attributed to the existence of MIP. Because of the inherent three-dimensional cavities formed in the MIP, more Trp molecules were selectively adsorbed on the specific recognition sites by rebinding groups, and the current response increases greatly. At the same time, the current response of MIP/ABPE is about 6 times that of MIP/CPE, which further confirm the current amplification effect of AB. Conversely, the significant decrease of peak current on NIP/ABPE $(0.06313 \mu \mathrm{A})$ can be attributed to the absence of specific binding sites and cavities in the NIP. According to the maximum peak current obtained on MIP/ABPE, MIP/ABPE can be used as a novel sensor for Trp detection with high sensitivity and selectivity. 


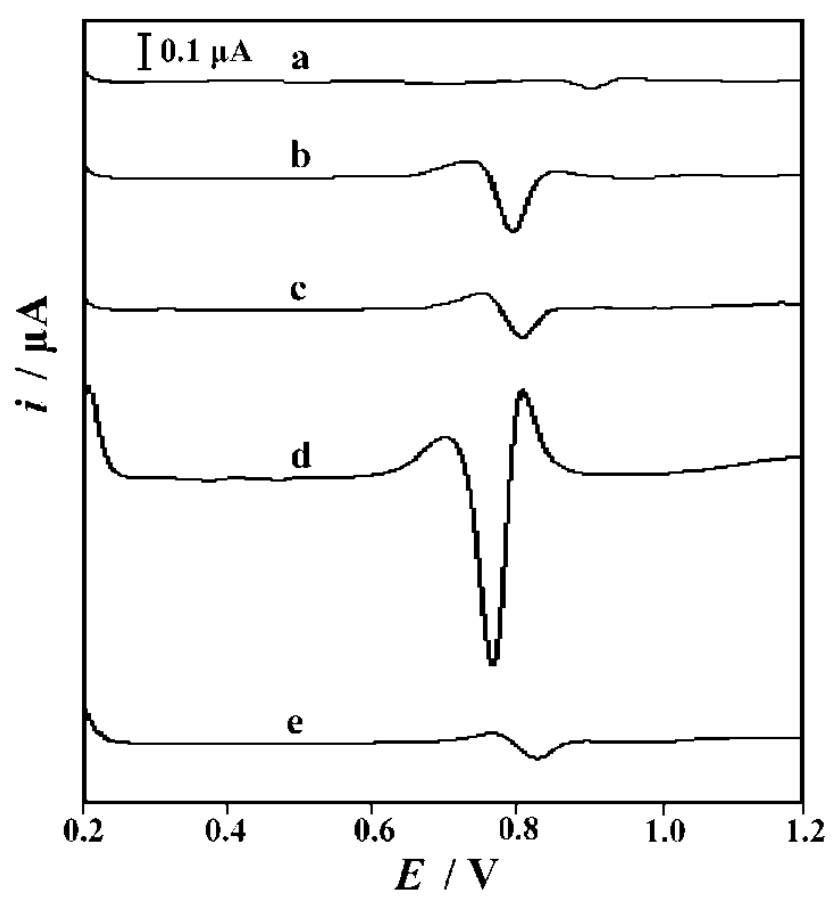

Figure 5. The second-order derivative linear sweep voltammograms of $0.1 \mathrm{mM}$ Trp recorded at different electrodes: (a) CPE, (b) ABPE, (c) MIP/CPE, (d) MIP/ABPE and (e) NIP/ABPE in 0.1 M phosphate buffer ( $\mathrm{pH}$ 7.0). Accumulation potential: $-0.1 \mathrm{~V}$, Accmulation time: $60 \mathrm{~s}$, scan rate: $0.1 \mathrm{~V} \mathrm{~s}^{-1}$.

By analyzing the relationship between the oxidation peak potential or current of Trp and the scanning rate, useful information concerning the electrochemical mechanism of Trp can be obtained. The effect of the scan rate ranging from 0.03 to $0.3 \mathrm{~V} \mathrm{~s}^{-1}$ on the electrochemical performance of Trp was evaluated by cyclic voltammetry (CV) on MIP/ABPE and the results were shown in Figure 6. It was found that Trp produced only one oxidation peak on MIP/ABPE, which indicated that the electrode reaction of Trp was completely irreversible. With the increase of the scan rate, The peak current of Trp increased linearly with the increase of the scan rate $\left(i=0.0051 v+0.2099\left(i: \mu \mathrm{A}, v: \mathrm{mV} \mathrm{s}^{-1}\right)\right.$, $\left.\mathrm{R}^{2}=0.9955\right)$, indicating that $\operatorname{Trp}$ is an adsorption control process on MIP/ABPE. The relationship between the oxidation peak potential and scan rate was also investigated, and it can be described as $E_{\mathrm{p}}=0.02594 \ln v+0.6365\left(E_{\mathrm{p}}: \mathrm{V}, v: \mathrm{mV} \mathrm{s}^{-1}\right), R^{2}=0.9949$. According to Laviron's theory [47], the slope was equal to RT/ $\alpha n$ F. The calculated value of $\alpha n$ was 0.9893 . For the completely irreversible electrode reaction process, $\alpha$ is assumed to be 0.5 . On the basis of the above discussion, $n$ was calculated to be 1.98 , indicating that there are two electrons involved in the oxidation of Trp on MIP/ABPE.
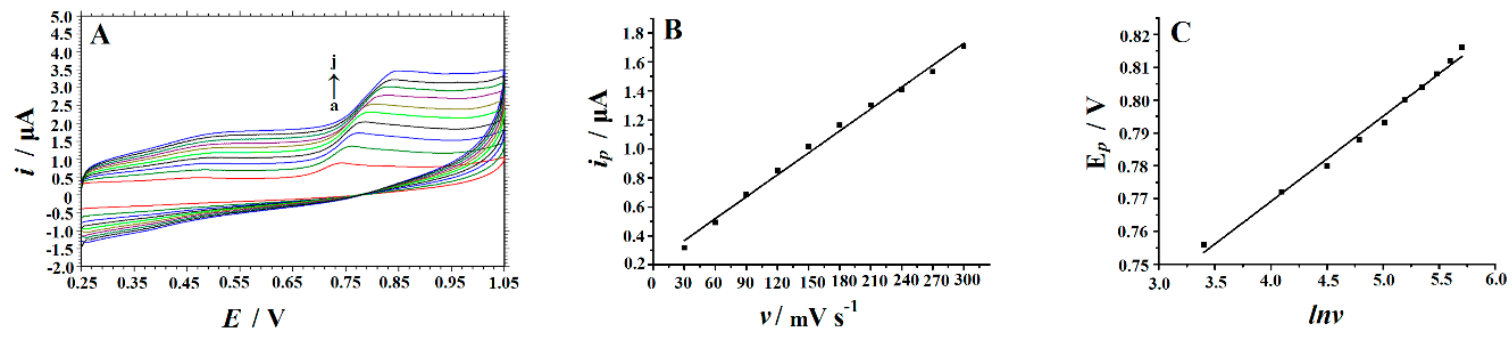

Figure 6. (A) The cyclic voltammograms of $0.1 \mathrm{mM}$ Trp in $0.1 \mathrm{M}$ phosphate buffer ( $\mathrm{pH} 7.0$ ) obtained on the MIP/ABPE at different scan rates (a-j: 30, 60, 90, 120, 150, 180, 210, 240, 270, $300 \mathrm{mV} \cdot \mathrm{s}^{-1}$ ); (B) The plot of the peak current versus the scan rate; $(\mathbf{C})$ The plot of the peak potential versus the Napierian logarithm of the scan rate. Accmulation potential: $-0.1 \mathrm{~V}$; Accmulation time: $60 \mathrm{~s}$; scan rate: $0.1 \mathrm{~V} \mathrm{~s}^{-1}$. 


\subsection{Optimization of Analytical Conditions}

All the following analysis conditions were optimized using the second-order derivative linear sweep voltammetry. The scanning potential range was $0.2 \sim 1.2 \mathrm{~V}$, the scanning rate was $0.1 \mathrm{~V} \mathrm{~s}^{-1}$, the supporting electrolyte was $0.1 \mathrm{M}$ phosphate buffer $(\mathrm{pH} 7.0)$ and the concentration of Trp was $0.1 \mathrm{mM}$.

\subsubsection{The Effect of the Concentrations of Chitosan}

The effect of the concentration of chitosan on the response of Trp on MIP/ABPE was tested. Five different concentrations of chitosan $(0.1 \mathrm{wt} \%, 0.5 \mathrm{wt} \%, 1.0 \mathrm{wt} \%, 2.0 \mathrm{wt} \%, 3.0 \mathrm{wt} \%)$ were examined. After accumulating at $-0.1 \mathrm{~V}$ for $180 \mathrm{~s}$ in $0.1 \mathrm{M}$ phosphate buffer ( $\mathrm{pH} 7.0$ ), it was found that the peak current of Trp increased with the increase of the concentration of chitosan up to $0.5 \mathrm{wt} \%$. However, after the concentration exceeded $0.5 \mathrm{wt} \%$, the peak current of Trp decreased. In the general condition, the viscosity of the chitosan solution increases with the increase of its concentration. A too high viscosity would induce a nonuniform thickness of the cast film; on the contrary, an unduly low viscosity would weaken the combination stability between the imprinting molecules and functional polymer, thereby debasing the selectivity of the imprinted electrode. Hence, $0.5 \mathrm{wt} \%$ of chitosan was selected as the optimum concentration (Figure 7A).

\subsubsection{The Effect of the Mass Ratio of Trp to Chitosan}

The appropriate ratio of Trp molecule to chitosan determines the number of binding sites for selective recombination of Trp. In order to improve the sensing performance of MIP/ABPE, the ratio of Trp to chitosan was discussed. The effect of the mass ratio of Trp to chitosan was studied in the range of 1:4 to 1:20 (Figure 7B). After accumulating at $-0.1 \mathrm{~V}$ for $180 \mathrm{~s}$ in a $0.1 \mathrm{M}$ phosphate buffer (pH 7.0), the results show that when the ratio decreases, the peak current of Trp increases and reaches its maximum at $1: 8$. This is related to the change in the number of available binding sites. When the amount of chitosan is sparse, the number of binding sites available is small. However, a high concentration of chitosan might lead to a non-selective electrochemical response to the template. Here, the mass ratio of 1:8 was the best and was chosen for subsequent experiments.

\subsubsection{The Effect of Trp-Chitosan Dropping Amount}

Different MIP/ABPEs were prepared by coating different volumes of Trp-chitosan on the surface of ABPE. Figure $7 \mathrm{C}$ showed the current response of $0.1 \mathrm{mM}$ Trp on different MIP/ABPEs after accumulating at $-0.1 \mathrm{~V}$ for $180 \mathrm{~s}$ in a $0.1 \mathrm{M}$ phosphate buffer ( $\mathrm{pH}$ 7.0). It was found that with the increase of the Trp-chitosan dropping amount, the peak current of Trp increased and the maximum current was obtained when the dropping amount reached $5 \mu \mathrm{L}$. However, the peak current of Trp decreased significantly when the dropping amount exceeded $5 \mu \mathrm{L}$. It is speculated that a very small dropping amount will reduce the number of effective imprinting sites on the surface of the electrode. A large dropping amount will lead to an increase in the film thickness, which will affect the conductivity of the electrode. For these reasons, the volume of Trp-chitosan suspension loaded on the ABPE surface was maintained at $5 \mu \mathrm{L}$.

\subsubsection{The Effect of the Solution $\mathrm{pH}$}

The effect of the solution $\mathrm{pH}$ on the peak current of $0.1 \mathrm{mM}$ Trp at MIP/ABPE was studied in a $0.1 \mathrm{M}$ phosphate buffer. After accumulating at $-0.1 \mathrm{~V}$ for $180 \mathrm{~s}$, the relationship between the oxidation current of Trp and the solution $\mathrm{pH}$ in the range of 4.91-7.89 was shown in Figure 7D. It was found that the oxidation current of Trp reached its maximum at $\mathrm{pH}$ 7.0. Therefore, $\mathrm{pH} 7.0$ was chosen as the best $\mathrm{pH}$ value for the Trp measurement in the following experiments. 


\subsubsection{Accumulation Potential and Accumulation Time}

The effect of the accumulated potential on the peak current of $0.1 \mathrm{mM}$ Trp was studied with a fixed accumulation time of $180 \mathrm{~s}$ in a $0.1 \mathrm{M}$ phosphate buffer ( $\mathrm{pH}$ 7.0). It can be seen that when the accumulation potential shifted from $-0.3 \mathrm{~V}$ to $-0.1 \mathrm{~V}$, the peak current increases gradually and the peak current of Trp was kept almost constant at $-0.1 \mathrm{~V}$ to $0.3 \mathrm{~V}$ (Figure 7E). Therefore, the best accumulation potential was chosen as $-0.1 \mathrm{~V}$. The effect of accumulation time on the oxidation peak current of $\operatorname{Trp}$ was also studied at a fixed accumulation potential of $-0.1 \mathrm{~V}$. It was found that the peak current of Trp increased with the increase of accumulation time. However, the oxidation peak current of Trp decreased slightly after $180 \mathrm{~s}$ (Figure 7F). Therefore, $180 \mathrm{~s}$ was chosen as the optimum accumulation time for Trp detection.
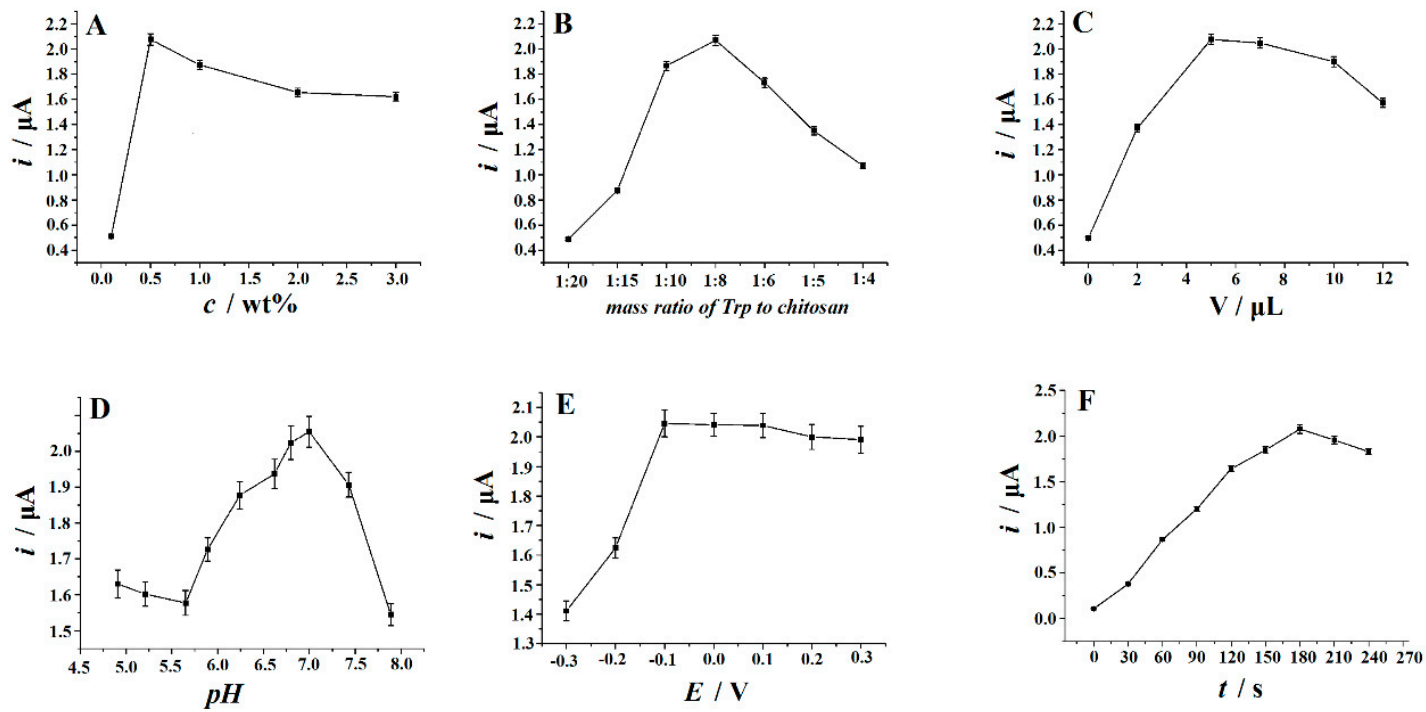

Figure 7. The effects of the concentration of chitosan (A), the mass ratio of Trp to chitosan (B), the dropping amount of Trp-chitosan suspension (C), the solution $\mathrm{pH}(\mathbf{D})$, the accumulation potential (E) and the accumulation time (F) on the oxidation peak current of $0.1 \mathrm{mM} \operatorname{Trp}$ at MIP/ABPE. When one parameter was changed, the other parameters were at their optimal values.

\subsection{Analytical Performance of the MIP/ABPE}

\subsubsection{Interference Study}

The important performance of MIP sensors is the selective recognition of template molecules. In order to evaluate the selectivity of MIP/ABPE to Trp, interference experiments were carried out in the presence of ascorbic acid (AA), uric acid (UA), dopamine (DA) and tyrosine (Tyr), which usually coexist with Trp in biological fluids and pharmaceutical formulations. The results are shown in Figure 8. Obviously, the current response of Trp on the MIP/ABPE was higher than other substances. In addition, as shown in column e, the peak current of Trp did not change significantly after adding 20-fold concentrations of AA, DA, UA and Tyr into the Trp solution, but the current values of Trp changed greatly on bare ABPE and NIP/ABPE. Additionally, it was found that 100-fold concentrations of $\mathrm{Na}^{+}, \mathrm{K}^{+}, \mathrm{Mg}^{2+}, \mathrm{Cu}^{2+}, \mathrm{Ca}^{2+}, \mathrm{Al}^{3+}, \mathrm{Pb}^{2+}, \mathrm{Cl}^{-}, \mathrm{NO}_{3}{ }^{-}, \mathrm{SO}_{4}{ }^{2-}$, oxalic acid, citric acid, glucose, lactic acid, tartaric acid almost did not interfere with the Trp oxidation signal on MIP/ABPE (signal change was less than 5\%). The effects of other amino acids such as glycine, alanine, valine, leucine, isoleucine, phenylalanine, histidine, aspartic acid, glutamic acid, lysine, arginine, serine, threonine, cysteine and proline on the determination of Trp were also studied. The results showed that any one of these amino acids (100 times content) did not interfere with the determination of Trp on MIP/ABPE. The results were summarized in Table S4 (Electronic Supplementary Material, ESM). The excellent selectivity might be attributed to the reason that the MIP/ABPE provided a thin imprinted polymer layer on the 
electrode surface. This layer had functional groups and selective cavities that specifically interacted with the template molecular Trp. During the imprinting process, the molecular space configuration was controlled by the large benzene ring in Trp molecules. After removing the imprinting molecules, the specific cavities were left in the chitosan network. the hydrogen bonds between chitosan and Trp improve the combination stability between the imprinting molecules and functional polymer, and the selectivity of MIP/ABPE.

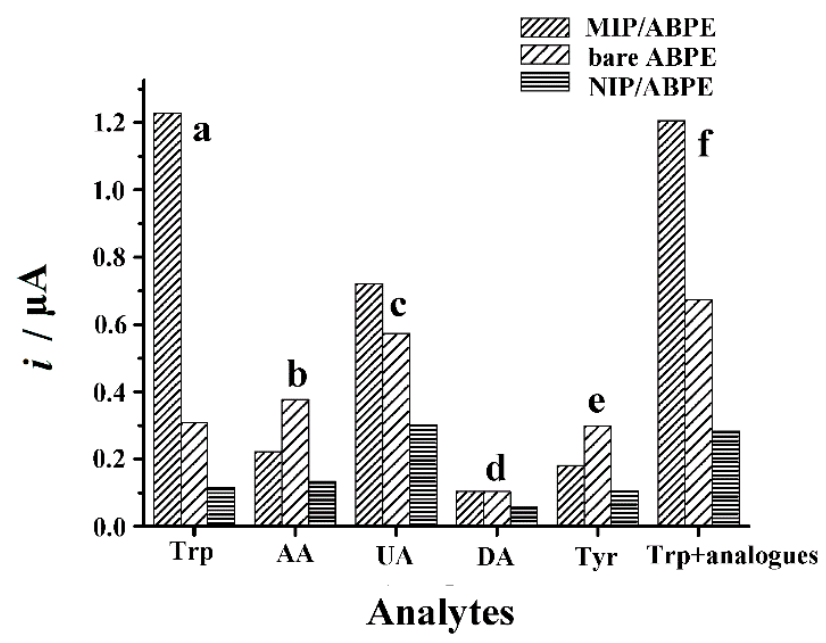

Figure 8. The selectivity of the MIP/ABPE: (a) $50 \mu \mathrm{M}$ Trp; (b) $1 \mathrm{mM}$ ascorbic acid (AA); (c) $1 \mathrm{mM}$ uric acid (UA); (d) $1 \mathrm{mM}$ dopamine (DA); (e) $1 \mathrm{mM}$ tyrosine (Tyr); (f) $50 \mu \mathrm{M}$ Trp mixed with 5 kinds of analogues $(50 \mu \mathrm{M}$ Trp + 1.0 mM AA + 1.0 mM UA + 1.0 mM DA + 1.0 mM Tyr). Supporting electrolyte: $0.1 \mathrm{M}$ phosphate buffer ( $\mathrm{pH} 7.0)$, incubation time: $120 \mathrm{~s}$, scan rate: $0.1 \mathrm{~V} \mathrm{~s}^{-1}$.

\subsubsection{Linear Range and Detection Limit}

The second derivative linear sweep voltammograms (Figure 9) show that the peak currents of Trp increase linearly with the increase of its concentration. Each point of the calibration plots corresponds to the average value obtained from three independent measurements. The calibration curve shows three linear regions $(0.01-4.0 \mu \mathrm{M}, 4.0-20 \mu \mathrm{M}$ and 20-100 $\mu \mathrm{M})$ in this relationship. The linear regression equations for these ranges were $i(\mu \mathrm{A})=0.0953 c(\mu \mathrm{M})+0.0044, i(\mu \mathrm{A})=0.0319 c(\mu \mathrm{M})+0.243$ and $i$ $(\mu \mathrm{A})=0.0144 c(\mu \mathrm{M})+0.6212$ with $R^{2}=0.9998,0.9989$ and 0.9960 respectively. The detection limits (LOD) were estimated by the formula of LOD $=3 \mathrm{~s} / \mathrm{m}, \mathrm{s}$ is the standard deviation of intercept and $\mathrm{m}$ is the slope of the regression line in the low concentration range [48]. The LOD of Trp were calculated to be $8.0 \mathrm{nM}$. The performance values of the developed sensor with other electrodes for Trp determination are compared in Table 1. From the linear range and detection limit, the performance of MIP/ABPE is superior to or comparable to other reported electrodes. In addition, the simple preparation process, low cost, high selectivity and environmentally friendly materials make the MIP/ABPE attractive in the Trp analysis. 
Table 1. The comparison of the efficiency of molecularly imprinted polymers (MIP)/acetylene black paste electrode (ABPE) with other modified electrodes in the electrochemical determination of Trp.

\begin{tabular}{|c|c|c|c|c|c|c|}
\hline Electrode & Technique & Supporting Electrolyte & Linear Range/ $\mu \mathrm{M}$ & Detection Limit/ $\mu \mathrm{M}$ & Effect of Tyr & References \\
\hline${ }^{\mathrm{a}} \mathrm{BuCh} / \mathrm{GCE}$ & ${ }^{\mathrm{m}} \mathrm{DPV}$ & phosphate buffer ( $\mathrm{pH} 7.0)$ & $2-60$ & 0.6 & seriously interfered & [16] \\
\hline b Au-NPs/GCE & DPV & phosphate buffer ( $\mathrm{pH}$ 2.5) & $0.09-50$ & 0.08 & seriously interfered & [17] \\
\hline${ }^{c}$ nanoAu-MWCNTs/GCE & DPV & phosphate buffer ( $\mathrm{pH} 7.4)$ & $5-100$ & 3 & seriously interfered & [18] \\
\hline $\mathrm{d}$ ETPGE & DPV & phosphate buffer ( $\mathrm{pH} 3.0$ ) & $0.5-50$ & 0.05 & 10 -fold concentration did not interfere & [19] \\
\hline e MWCNTs/GCE & DPV & phosphate Buffer ( $\mathrm{pH} 3.5$ ) & $0.25-100$ & 0.027 & 5 -fold concentration did not interfere & [20] \\
\hline f PGA/CNTPE & ${ }^{\mathrm{n}} \mathrm{CV}$ & phosphate buffer ( $\mathrm{pH} 6.0$ ) & $0.05-100$ & 0.01 & not mentioned & [21] \\
\hline g MWCNTs/CPE & Amperometry & phosphate buffer ( $\mathrm{pH} 3.0)$ & $0.6-9.0 ; 10.0-100$ & 0.033 & seriously interfered & [22] \\
\hline h PSA/GCE & DPV & phosphate buffer (pH 3.5) & $0.05-10$ & 0.0068 & not mentioned & [23] \\
\hline i EGPU-tAuNP & DPV & Britton-Robinson buffer ( $\mathrm{pH}$ 7.4) & $0.6-2.0$ & 0.053 & not mentioned & [24] \\
\hline j B-CD/MWCNTs/GCE & DPV & phosphate buffer (pH 3.0) & $1.5-30.5$ & 0.07 & 4-fold concentration did not interfere & [25] \\
\hline $\mathrm{k}_{\mathrm{rGO} / \mathrm{SnO}_{2} / \mathrm{GCE}}$ & DPV & phosphate buffer ( $\mathrm{pH}$ 7.0) & $1-100$ & 0.04 & 30-fold concentration did not interfere & [26] \\
\hline${ }^{1} \mathrm{Ta}_{2} \mathrm{O}_{5}$-rGO-GCE & second-order derivative LSV & phosphate buffer (pH 6.0) & $1-8 ; 8-80 ; 80-800$ & 0.87 & N.A & [27] \\
\hline MIP/ABPE & second-order derivative LSV & phosphate buffer ( $\mathrm{pH} 3.0$ ) & $0.01-4 ; 4-20 ; 20-100$ & 0.008 & 20 -fold concentration did not interfere & This work \\
\hline
\end{tabular}

${ }^{a}$ butyrylcholine modified glassy carbon electrode; ${ }^{b}$ gold nanoparticles modified glassy carbon electrode; ${ }^{c}$ gold nanoparticles decorated multiwalled carbon nanotube modified glassy carbon electrode; ${ }^{\mathrm{d}}$ electrochemically treated pencil graphite electrode; ${ }^{\mathrm{e}}$ acid-treated multi-walled carbon nanotubes modified glassy carbon electrode; ${ }^{\mathrm{f}}$ poly-glutamic acid film modified carbon paste electrode; ${ }^{g}$ multi-walled carbon nanotube modified carbon paste electrode; ${ }^{h}$ Poly(sulfosalicylic acid) modified glassy carbon electrode; ${ }^{i}$ Gold nanoparticles modified graphitepolyurethane composite electrode; ${ }^{j} \beta$-cyclodextrin incorporated with multi-walled carbon nanotube modified glassy carbon electrode; ${ }^{k}$ reduced graphene oxide decorated with

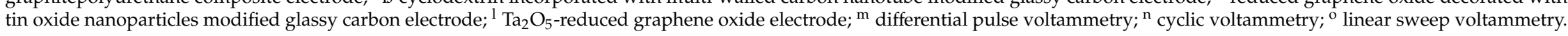



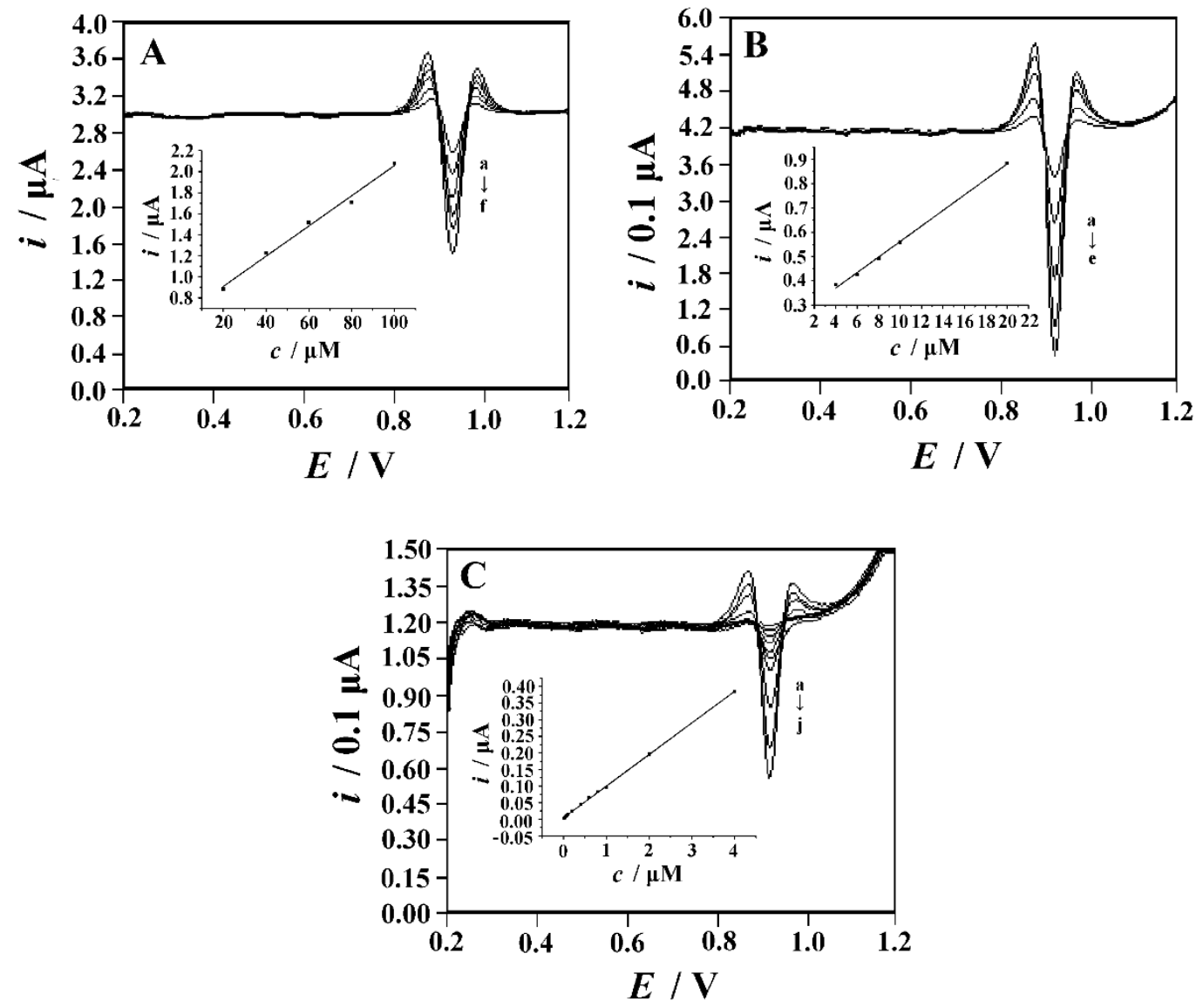

Figure 9. The second-order derivative linear scan voltammograms obtained at MIP/ABPE in a $0.1 \mathrm{M}$ phosphate buffer ( $\mathrm{pH} 7.0$ ) and different concentrations of Trp: (A) from a to f : 10, 20, 40, 60, 80, $100 \mu \mathrm{M}$; (B) from a to e: 1.0, 2.0, 4.0, 6.0, $8.0 \mu \mathrm{M}$; (C) from a to j: 0.01, 0.02, 0.04, 0.06, 0.08, 0.1, 0.2, 0.4, 0.6, 0.8 $\mu \mathrm{M}$, The inset of (A-C) shows the calibration curves of Trp in the range of 20-100 $\mu \mathrm{M}, 4-20 \mu \mathrm{M}$ and $0.01-4$ $\mu \mathrm{M}$, respectively. Accumulation potential: $-0.1 \mathrm{~V}$, accumulation time: $180 \mathrm{~s}$, scan rate: $0.1 \mathrm{~V} \mathrm{~s}^{-1}$.

\subsubsection{Reproducibility, Reusability and Long-Term Stability}

Reproducibility and reusability are another two critical parameters for evaluating the performance of a sensor. The current response of $0.1 \mathrm{mM}$ Trp on the same MIP/ABPE was measured repeatedly in a $0.1 \mathrm{M}$ phosphate buffer ( $\mathrm{pH}$ 7.0). After each measurement, the imprinted electrode was treated with repetitive potential scanning in a $0.1 \mathrm{M}$ phosphate buffer ( $\mathrm{pH}$ 7.0) to remove the template molecules. A relative standard deviation (RSD) of $1.70 \%$ (Table S2) was obtained $(n=7)$, which showed that the MIP/ABPE had good reusability. The reproducibility of the MIP/ABPE was determined by comparing the current responses of eight MIP/ABPEs, which were fabricated according to the same steps. An RSD of $4.18 \%$ (Table S3) was obtained, which showed that the reproducibility of the MIP/ABPE was acceptable. In addition, the stability of MIP/ABPE was also studied. In the first 10 days of storage, the response of the sensor to Trp did not deteriorate significantly. After 20 days of storage, the sensor maintained about $91 \%$ (Table S4) of its initial current response, indicating that the prepared MIP/ABPE had good long-term stability.

\subsubsection{Practical Application}

To explore the practical application of MIP/ABPE, it was used to determine Trp in human serum samples and compound amino acid injections. A serum sample solution was prepared according to our previous report [11,49-52]. The compound amino acid injection was diluted 100 times with distilled water and used directly. A part of the sample solution was added to a $0.1 \mathrm{M}$ phosphate buffer ( $\mathrm{pH} 7.0$ ). 
In order to prevent the matrix effect, the standard addition method was used to determine Trp content in samples. As shown in Tables 2 and 3, the recoveries of human serum samples and amino acid injection samples are 97.3-102.4\% and 98.3-104.2\%, respectively. The results show that the electrode has high accuracy and selectivity for the determination of Trp in drugs and biological samples.

Table 2. The results for the determination of Trp in compound amino acid injections $(n=4)$.

\begin{tabular}{ccccc}
\hline Sample ID & Label Values/g L & Found $/ \mathbf{g L}^{-\mathbf{1}}$ & RSD/\% & Recovery/\% \\
\hline $\mathrm{A}^{\mathrm{a}}$ & 0.430 & 0.438 & 2.4 & 102.4 \\
$\mathrm{~B}^{\mathrm{a}}$ & 0.700 & 0.695 & 2.8 & 98.6 \\
$\mathrm{C}^{\mathrm{a}}$ & 0.900 & 0.913 & 3.1 & 97.3 \\
$\mathrm{D}^{\mathrm{b}}$ & 1.000 & 0.988 & 2.2 & 101.8 \\
\hline
\end{tabular}

${ }^{a}$ The sample was obtained from Xuzhou, the Fifth Pharmaceutical Corporation. ${ }^{\mathrm{b}}$ The sample was obtained from Guangzhou Green Cross Pharmaceutical Corporation.

Table 3. The results for the determination of Trp in blood serum samples $(n=4)$.

\begin{tabular}{cccccc}
\hline Sample ID & Found $/ \boldsymbol{\mu M}$ & RSD/\% & Added $/ \boldsymbol{\mu M}$ & $\begin{array}{c}\text { Total } \\
\text { Found } / \boldsymbol{\mu M}\end{array}$ & Recovery/\% \\
\hline A & 2.67 & 2.7 & 3.0 & 5.74 & 102.3 \\
B & 3.45 & 2.3 & 4.0 & 7.52 & 101.8 \\
C & 4.28 & 2.5 & 4.0 & 8.45 & 104.2 \\
D & 3.37 & 2.9 & 3.0 & 6.32 & 98.3 \\
\hline
\end{tabular}

\section{Conclusions}

In the present paper, a molecularly imprinted chitosan film was prepared on the surface of an acetylene black paste electrode by the drop-coating method. After removing the template molecule, the molecularly imprinted membrane provides a highly tryptophan-affinity interface. Under the optimum conditions, a wider linear range and a lower detection limit are obtained. In addition, the imprint electrode has other advantages including simple fabrication, low cost, good repeatability and fast response; all of them make it hold great promise in the electro-analysis of Trp in real samples.

Supplementary Materials: The following are available online at http://www.mdpi.com/2218-273X/9/7/294/s1, Table S1. Influence of coexisting substances on the determination of $10 \mu \mathrm{M}$ Trp; Table S2. Reusability of MIP/ABPE; Table S3. Reproducibility of MIP/ABPE; Table S4. The storage stability of MIP/ABPE.

Author Contributions: P.D. and Q.H. conceived and designed the experiments; Y.T., Y.W., Z.D. and J.L. performed the experiments; Y.W., Y.T., P.D. and Z.D. analyzed the data; J.L., G.L., and Q.H. contributed reagents/materials/analysis tools; Q.H. and P.D. wrote the paper.

Funding: This work was supported by Project of Key Laboratory of Functional Organometallic Materials, University of Hunan Province (GN19K01, GN19K05), Project of Key Laboratory of Functional Metal-Organic Compounds of Hunan Province (MO19K08), and Project of Hengyang Normal University (HXKJ201912). Also by Doctoral Program Construction of Hunan University of Technology, Postgraduates Innovation Fund of HUT, the NSFC (61703152), Project of Science and Technology of Hunan Province Education Department (18A273, 18C0522) and Hunan Provincial Natural Science Foundation (2016JJ4010, 2018JJ34).

Conflicts of Interest: The authors declare no conflict of interest.

\section{References}

1. Fiorucci, A.R.; Cavalheiro, É.T.G. The use of carbon paste electrode in the direct voltammetric determination of tryptophan in pharmaceutical formulations. J. Pharm. Biomed. Anal. 2002, 28, 909-915. [CrossRef]

2. Kochen, W.; Steinhart, H. L-Tryptophan: Current Prospects in Medicine and Drug Safety; Walter de-Gruyter: Berlin, Germany, 1994.

3. Pi, L.G.; Tang, A.G.; Mo, X.M.; Luo, X.B.; Ao, X. More rapid and sensitive method for simultaneous determination of tryptophan and kynurenic acid by HPLC. Clin. Biochem. 2009, 42, 420-425. [PubMed] 
4. Michalczuk, L.; Bialek, K.; Cohen, J.D. Rapid determination of free tryptophan in plant samples by gas chromatography-selected ion monitoring mass spectrometry. J. Chromatogr. A 1992, 596, 294-298. [CrossRef]

5. Huynh, T.K.X.; Leipzig-Pagani, E. Quantitative thin layer chromatography on cellulose II. Selected applications: Lower alcohols, tryptophan enantiomers, gold and platinum. J. Chromatogr. A 1996, 746, 261-268. [CrossRef]

6. Verma, K.K.; Jain, A.; Gasparič, J. Spectrophotometric determination of tryptophan by reaction with nitrous acid. Talanta 1988, 35, 35-39. [CrossRef]

7. Othman, A.M.; Li, S.; Leblanc, R.M. Enhancing selectivity in spectroflurimetric determination of tryptophan by using graphene oxide nanosheets. Anal. Chim. Acta 2013, 787, 226-232. [CrossRef] [PubMed]

8. Qiu, H.; Luo, C.; Sun, M.; Lu, F.; Fan, L.; Li, X. Determination of L-tryptophan based on graphene oxide-magnetite-molecularly imprinted polymers and chemiluminescence. Talanta 2012, 98, 226-230. [CrossRef] [PubMed]

9. Makriyannis, A.A.; Kheir, A.E.; Ayad, M.M.; Hassan, W.S.; Metwally, M.M.F. Derivative spectroscopy in conjunction with thin layer chromatography applied for determination of mixtures of amino acids in baby food. Spectrosc. Lett. 1997, 30, 649-660. [CrossRef]

10. López-Cueto, G.; Rodríguez-Medina, J.F.; Ubide, C. Individual kinetic determinations using partial least squares calibration. Analyst 1997, 122, 519-523. [CrossRef]

11. He, Q.; Liu, J.; Liu, X.; Li, G.; Chen, D.; Deng, P.; Liang, J. Fabrication of Amine-Modified Magnetite-Electrochemically Reduced Graphene Oxide Nanocomposite Modified Glassy Carbon Electrode for Sensitive Dopamine Determination. Nanomaterials 2018, 8, 194. [CrossRef]

12. He, Q.; Wu, Y.; Tian, Y.; Li, G.; Chen, D. Facile Electrochemical Sensor for Nanomolar Rutin Detection Based on Magnetite Nanoparticles and Reduced Graphene Oxide Decorated Electrode. Nanomaterials 2019, 9, 115. [CrossRef] [PubMed]

13. He, Q.; Liu, J.; Liu, X.; Li, G.; Chen, D.; Deng, P.; Liang, J. A promising sensing platform toward dopamine using $\mathrm{MnO}_{2}$ nanowires/electro-reduced graphene oxide composites. Electrochim. Acta 2019, 296, 683-692. [CrossRef]

14. He, Q.; Liu, J.; Liu, X.; Li, G.; Deng, P.; Liang, J. Manganese dioxide Nanorods/electrochemically reduced graphene oxide nanocomposites modified electrodes for cost-effective and ultrasensitive detection of Amaranth. Colloids Surf. B 2018, 172, 565-572. [CrossRef] [PubMed]

15. He, Q.; Liu, J.; Liu, X.; Li, G.; Deng, P.; Liang, J. Preparation of $\mathrm{Cu}_{2} \mathrm{O}$-Reduced Graphene Nanocomposite Modified Electrodes towards Ultrasensitive Dopamine Detection. Sensors 2018, 18, 199. [CrossRef] [PubMed]

16. Jin, G.P.; Lin, X.Q. The electrochemical behavior and amperometric determination of tyrosine and tryptophan at a glassy carbon electrode modified with butyrylcholine. Electrochem. Commun. 2004, 6, 454-460. [CrossRef]

17. Li, C.; Ya, Y.; Zhan, G. Electrochemical investigation of tryptophan at gold nanoparticles modified electrode in the presence of sodium dodecylbenzene sulfonate. J. Colloids. Surf. B 2010, 76, 340-345. [CrossRef]

18. Kooshki, M.; Abdollahi, H.; Bozorgzadeh, S.; Haghighi, B. Second-order data obtained from differential pulse voltammetry:Determination of tryptophan at a gold nanoparticles decorated multiwalled carbon nanotube modified glassy carbon electrode. Electrochim. Acta 2011, 56, 8618-8624. [CrossRef]

19. Özcan, A.; Sahin, Y. A novel approach for the selective determination of tryptophan in blood serum in the presence of tyrosine based on the electrochemical reduction of oxidation product of tryptophan formed in situ on graphite electrode. Biosens. Bioelectron. 2012, 31, 26-31. [CrossRef]

20. Wu, F.H.; Zhao, G.C.; Wei, X.W.; Yang, Z.S. Electrocatalysis of tryptophan at multi-walled carbon nanotube modified electrode. Microchim. Acta 2004, 144, 243-247. [CrossRef]

21. Liu, X.; Luo, L.; Ding, Y.; Ye, D. Poly-glutamic acid modified carbon nanotube-doped carbon paste electrode for sensitive detection of L-tryptophan. Bioelectrochemistry 2011, 82, 38-45. [CrossRef]

22. Thomas, T.; Mascarenhas, R.J.; D'Souza, O.J.; Martis, P.; Dalhalle, J.; Swamy, B.E.K. Multi-walled carbon nanotube modified carbon paste electrode as a sensor for the amperometric detection of L-tryptophan in biological samples. J. Colloid. Interface. Sci. 2013, 402, 223-229. [CrossRef] [PubMed]

23. Ba, X.; Luo, L.; Ding, Y.; Liu, X. Determination of l-tryptophan in the presence of ascorbic acid and dopamine using poly(sulfosalicylic acid) modified glassy carbon electrode. Sens. Actuators B Chem. 2013, 187, $27-32$. [CrossRef] 
24. Mattioli, I.A.; Baccarin, M.; Cervini, P.; Cavalheiro, É.T.G. Electrochemical investigation of a graphite-polyurethane composite electrode modified with electrodeposited gold nanoparticles in the voltammetric determination of tryptophan. J. Electroanal. Chem. 2019, 835, 212-219. [CrossRef]

25. Mukdasai, S.; Poosittisak, S.; Ngeontae, W.; Srijaranai, S. A highly sensitive electrochemical determination of L-tryptophan in the presence of ascorbic acid and uric acid using in situ addition of tetrabutylammonium bromide on the $B$-cyclodextrin incorporated multi-walled carbon nanotubes modified electrode. Sens. Actuators B Chem. 2018, 272, 518-525. [CrossRef]

26. Haldorai, Y.; Yeon, S.-H.; Huh, Y.S.; Han, Y.-K. Electrochemical determination of tryptophan using a glassy carbon electrode modified with flower-like structured nanocomposite consisting of reduced graphene oxide and $\mathrm{SnO}_{2}$. Sens. Actuators B Chem. 2017, 239, 1221-1230. [CrossRef]

27. Zhou, S.; Deng, Z.; Wu, Z.; Xie, M.; Tian, Y.; Wu, Y.; Liu, J.; Li, G.; He, Q. Ta $2 \mathrm{O}_{5} / \mathrm{rGO}$ Nanocomposite Modified Electrodes for Detection of Tryptophan through Electrochemical Route. Nanomaterials 2019, 9, 811. [CrossRef] [PubMed]

28. Hammam, M.A.; Abdel-Halim, M.; Madbouly, A.; Wagdy, H.A.; Nashar, R.M.E. Computational design of molecularly imprinted polymer for solid phase extraction of moxifloxacin hydrochloride from Avalox ${ }^{\circledR}$ tablets and spiked human urine samples. Microchem. J. 2019, 148, 51-56. [CrossRef]

29. Ahmad, O.S.; Bedwell, T.S.; Esen, C.; Garcia-Cruz, A.; Piletsky, S.A. Molecularly imprinted polymers in electrochemical and optical sensors. Trends Biotechnol. 2019, 37, 294-309. [CrossRef] [PubMed]

30. Guoning, C.; Pengqi, G.; Yan, W.; Lu, W.; Qiang, F. Preparation of molecularly imprinted polymers and application in a biomimetic biotin-avidin-ELISA for the detection of bovine serum albumin. Talanta 2019, 198, 55-62. [CrossRef]

31. Beluomini, M.A.; da Silva, J.L.; de Sá, A.C.; Buffon, E.; Stradiotto, N.R. Electrochemical sensors based on molecularly imprinted polymer on nanostructured carbon materials: A review. J. Electroanal. Chem. 2019, 840, 343-366. [CrossRef]

32. Qader, B.; Baron, M.; Hussain, I.; Sevilla, J.M.; Gonzalez-Rodriguez, J. Electrochemical determination of disulfoton using a molecularly imprinted poly-phenol polymer. Electrochim. Acta 2019, 295, 333-339. [CrossRef]

33. Roushani, M.; Jalilian, Z.; Nezhadali, A. A novel electrochemical sensor based on electrode modified with gold nanoparticles and molecularly imprinted polymer for rapid determination of trazosin. Colloids Surf. B Biointerfaces 2018, 172, 594-600. [CrossRef] [PubMed]

34. Chatterjee, T.N.; Das, D.; Roy, R.B.; Tudu, B.; Bandyopadhyay, R. Development of a nickel hydroxide nanopetal decorated molecular imprinted polymer based electrode for sensitive detection of epigallocatechin-3-gallate in green tea. Sens. Actuators B Chem. 2019, 283, 69-78. [CrossRef]

35. Sah, A.K.; Dewangan, M.; Suresh, P.K. Potential of chitosan-based carrier for periodontal drug delivery. Colloids Surf. B Biointerfaces 2019, 178, 185-198. [CrossRef] [PubMed]

36. Jimtaisong, A.; Sarakonsri, T. Chitosan intercalated bentonite as natural adsorbent matrix for water-soluble sappanwood dye. Int. J. Biol. Macromol. 2019, 129, 737-743. [CrossRef] [PubMed]

37. Liu, G.; Zhang, L.; Mao, S.; Rohani, S.; Lu, J. Zwitterionic chitosan-silica-PVA hybrid ultrafiltration membranes for protein separation. Sep. Purif. Technol. 2015, 152, 55-63. [CrossRef]

38. Guo, W.; Pi, F.; Zhang, H.; Sun, J.; Sun, X. A novel molecularly imprinted electrochemical sensor modified with carbon dots, chitosan, gold nanoparticles for the determination of patulin. Biosens. Bioelectron. 2017, 98 , 299-304. [CrossRef] [PubMed]

39. Wu, S.; Dai, X.; Cheng, T.; Li, S. Highly sensitive and selective ion-imprinted polymers based on one-step electrodeposition of chitosan-graphene nanocomposites for the determination of Cr(VI). Carbohyd. Polym. 2018, 195, 199-206. [CrossRef] [PubMed]

40. Liu, B.; Lian, H.T.; Yin, J.F.; Sun, X.Y. Dopamine molecularly imprinted electrochemical sensor based on graphene-chitosan composite. Electrochim. Acta 2012, 75, 108-114. [CrossRef]

41. Xia, J.; Cao, X.; Wang, Z.; Yang, M.; Xia, Y. Molecularly imprinted electrochemical biosensor based on chitosan/ionic liquid-graphene composites modified electrode for determination of bovine serum albumin. Sens. Actuators B Chem. 2016, 225, 305-311. [CrossRef]

42. Deng, P.; Xu, Z.; Feng, Y. Acetylene black paste electrode modified with graphene as the voltammetric sensor for selective determination of tryptophan in the presence of high concentrations of tyrosine. Mater. Sci. Eng. C 2014, 35, 54-60. [CrossRef] [PubMed] 
43. Deng, P.; Xu, Z.; Zeng, R.; Ding, C. Electrochemical behavior and voltammetric determination of vanillin based on an acetylene black paste electrode modified with graphene-polyvinylpyrrolidone composite film. Food Chem. 2015, 180, 156-163. [CrossRef] [PubMed]

44. Ma, X.; Chen, R.; Zheng, X.; Youn, H.; Chen, Z. Preparation of molecularly imprinted CS membrane for recognizing naringin in aqueous media. Polym. Bull. 2011, 66, 853-863. [CrossRef]

45. Motahari, A.; Omrani, A.; Rostami, A.A.; Ehsani, M. Preparation and characterization of a novel epoxy based nanocomposite using tryptophan as an eco-friendly curing agent. Thermochim. Acta 2013, 574, $38-46$. [CrossRef]

46. Wang, Q.; Wang, Y.; Liu, S.; Wang, L.; Gao, F.; Gao, F.; Sun, W. Voltammetric detection of bisphenol a by a chitosan-graphene composite modified carbon ionic liquid electrode. Thin Solid Films 2012, 520, 4459-4464. [CrossRef]

47. Laviron, E. Adsorption, autoinhibition and autocatalysis in polarography and in linear potential sweep voltammetry. J. Electroanal. Chem. Interf. Electrochem. 1974, 52, 355-393. [CrossRef]

48. González, A.G.; Herrador, M.Á. A practical guide to analytical method validation, including measurement uncertainty and accuracy profiles. Trend. Anal. Chem. 2007, 26, 227-238. [CrossRef]

49. Deng, P.; Fei, J.; Feng, Y. Sensitive voltammetric determination of tryptophan using an acetylene black paste electrode modified with a Schiff's base derivative of chitosan. Analyst 2011, 136, 5211-5217. [CrossRef]

50. He, Q.; Tian, Y.; Wu, Y.; Liu, J.; Li, G.; Deng, P.; Chen, D. Electrochemical sensor for rapid and sensitive detection of tryptophan by a $\mathrm{Cu}_{2} \mathrm{O}$ nanoparticles-coated reduced graphene oxide nanocomposite. Biomolecules 2019, 9, 176. [CrossRef]

51. Magesa, F.; Wu, Y.; Tian, Y.; Vianney, J.-M.; Buza, J.; He, Q.; Tan, Y. Graphene and graphene like 2D graphitic carbon nitride: Electrochemical detection of food colorants and toxic substances in environment. Trends Environ. Anal. Chem. 2019. [CrossRef]

52. He, Q.; Liu, J.; Xia, Y.; Tuo, D.; Deng, P.; Tian, Y.; Chen, D. Rapid and sensitive voltammetric detection of rhodamine $\mathrm{B}$ in chili-containing foodstuffs using $\mathrm{MnO}_{2}$ nanorods/electro-reduced graphene oxide composite. J. Electrochem. Soc. 2019. [CrossRef]

(C) 2019 by the authors. Licensee MDPI, Basel, Switzerland. This article is an open access article distributed under the terms and conditions of the Creative Commons Attribution (CC BY) license (http://creativecommons.org/licenses/by/4.0/). 